\title{
Biochemical composition during growth and starvation of early larval stages of cultured spiny lobster (Jasus edwardsii) phyllosoma
}

\author{
Arthur J. Ritar ${ }^{a}$, Graeme A. Dunstan ${ }^{b}$, Bradley J. Crear ${ }^{\mathrm{a}}$, Malcolm R. Brown ${ }^{\mathrm{b}}$ \\ ${ }^{a}$ Marine Research Laboratories, Tasmanian Aquaculture and Fisheries Institute, University \\ of Tasmania, Nubeena Crescent, Taroona, Tasmania 7053, Australia. \\ ${ }^{\mathrm{b}}$ CSIRO Marine Research, GPO Box 1538 Hobart, Tasmania 7001, Australia. \\ * Corresponding author: Arthur.Ritar@utas.edu.au)
}

\begin{abstract}
We examined biochemical changes accompanying feeding and starvation from hatch to Stage VI (day 74 after hatch) in spiny lobster, Jasus edwardsii, phyllosoma larvae. Larval dry weights $(\mathrm{dw})$ increased 17-fold from hatch $(80 \pm 1 \mu \mathrm{g})$ to Stage VI $(1415 \pm 44 \mu \mathrm{g})$. Larvae starved for 6-11 days at Stages II, IV and VI were 14-40\% lighter than their fed counterparts fed enriched Artemia. The increases and losses in total dw during feeding and starvation were associated with changes in the content of protein (constituting 31.4-41.7\% of $\mathrm{dw}$ ) and carbohydrate (constituting 2.6-5.3\% of dw), while larger changes in lipid content indicated its greater importance as an energy substrate. Lipid content increased from $7.9 \%$ of dw at hatch to its highest of $12.5 \%$ at Stage IV, but declined by $50 \%$ or more during starvation. This suggests that protein, carbohydrate and lipid are all important energy stores, although lipids are catabolised at a greater rate during food deprivation. The principal lipid class was polar lipid (79-92\% of total lipid), followed by sterol (6-20\%), with triacylglycerol and other lipid classes at $<2 \%$. Polar lipids were catabolized and sterols were conserved during starvation. Changes in the fatty acid profile had mostly occurred before the first moult at day 8 after hatch, with gradual changes thereafter to Stage VI, reflecting their abundance in the Artemia diet. There was some conservation of the major essential fatty acids (EFA), 20:4n-6, 20:5n-3, 22:6n-3, and the fatty acid profile showed large gains in the $\mathrm{C}_{18}$ PUFA, 18:1n-9, 18:2n-6. Ascorbic acid content increased 10 -fold from hatch to the end of Stage I ( 36 and $333 \mu \mathrm{g} \mathrm{g}^{-1} \mathrm{dw}$, respectively), while the content at the end of Stage II was higher in fed than starved larvae (439 and $174 \mu \mathrm{g} \mathrm{g}^{-1} \mathrm{dw}$, respectively). Our study will assist in the development of alternatives to nutritionally incomplete diets, such as live ongrown Artemia, to meet the requirements of phyllosoma in culture.
\end{abstract}

Keywords: Artemia; Ascorbic acid; Fatty acid; Jasus edwardsii; Nutrition; Phyllosoma; Spiny lobster; Starvation.

\section{Introduction}

The marine farming of spiny lobsters, including Jasus edwardsii, is being attempted in Australia and New Zealand as a means of expanding production beyond the lucrative but fully exploited wild fisheries. The mass quantities of pueruli needed as seed for such an enterprise requires closure of the life cycle through larval culture. It is therefore important to understand the metabolic changes occurring in phyllosoma larvae as they progress through developmental stages with a view to producing efficient diets that sustain growth. The biochemical changes occurring in larvae during feeding and starvation are indicators of their nutritional requirements and are an important basis for determining suitable diets 
during larval culture (Olsen, 1998). However, nutritional studies on phyllosoma of spiny lobster are rare because of the difficulty in hatchery rearing through the long larval phase which may last up to 24 months in the wild (Phillips and Sastry, 1980; Booth and Phillips, 1994) and require 17-22 moults (Booth, 1994; Kittaka, 1994) through 11 recognised morphological stages (Lesser, 1978). The wild pelagic larvae undergo a critical metamorphosis to the puerulus stage before settling inshore in protected rocky areas. Juvenile development to adulthood then occurs in the benthic habitat before maturation, mating, egg extrusion and embryonic development to larval hatch, leading to completion of the life cycle.

During starvation of crustaceans, at all life stages including larvae, there are three distinct phases of biomass degradation (Anger, 2001). Initially, energy-rich lipid reserves are preferentially mobilised, reflected in decreasing lipid:protein ratios, which is typical of short-term food deprivation. When much of the accessible lipid pool has been depleted, proteins are increasingly utilised. A significant part of the lipid pool is bound in crucial cell structures such as membranes, and hence is normally unavailable for energy metabolism. This phase of predominantly protein catabolism is indicated by an increase in the lipid:protein ratio and reflects the degradation of structures such as muscle and nervous tissue. In the final phase of starvation prior to death, structural lipids may also be degraded, so that the lipid:protein ratio decreases again. In this condition, the larvae have passed their point-of-no-return and do not recover after re-feeding (Mikami et al., 1995; Abrunhosa and Kittaka, 1997). The effects of feeding and starvation on development of phyllosoma have not been examined in terms of accumulation and loss in the major body components of protein, lipid and carbohydrate. However, a recent study in J. edwardsii, which focussed on the changes in fatty acids immediately after larval hatch, suggested that the inclusion of essential fatty acids (EFA) in the diet was important, although it was inconclusive due to the short period of starvation or feeding for only 8 days, which falls just short of the first moult (Smith et al., $2003 \mathrm{c}$ ). Fatty acids are important for the nutrition of juvenile and adult crustaceans, in that they are used as energy sources as well as to maintain the integrity of cellular membranes. For decapod crustaceans, arachidonic acid (ARA, 20:4n6), eicosapentaenoic acid (EPA, 20:5n-3) and docosahexaenoic acid (DHA, 22:6n-3) are regarded as essential (Castell, 1982; Kanazawa, 1982; Cahu and Fauvel, 1986; Sargent, 1995) and must be supplied in the diet (Kanazawa et al., 1979; Deering et al., 1997). These long-chain polyunsaturated fatty acids (PUFA) are preferentially conserved, i.e. their rate of catabolism or loss is low (Sargent and Whittle, 1981).

Few studies have been done in larval decapods but Jones et al. (1979) and Teshima et al. (1992) established that these fatty acids were essential for larvae of Penaeus japonicus, and Kurmaly et al. (1989) for P. monodon larvae. Knowledge of the requirements for EFA during early larval stages is a useful aid in diet development for achieving successful propagation in species which are difficult to rear (Olsen, 1998). The relative importance of specific fatty acids in early larval stages of crustaceans may be elucidated by analyses of wild-caught larvae, newly-hatched larvae and larvae subjected to a period of starvation (Olsen, 1998). The changes in lipid classes and fatty acids were recently described up to Stage XI of larval development for J. edwardsii phyllosoma from the wild (Phleger et al., 2001) and of the fatty acids during feeding and starvation shortly after hatch (Smith et al., 2003c).

Artemia diets, which are used for the hatchery rearing of many marine crustacean larvae, are attractive to phyllosoma. Although Artemia are naturally low in DHA, EPA and ARA, they can be enriched with lipids high in these EFA. The amounts of EFA, and the ratio of individual EFA to each other, can be important to ensure normal development of fish larvae (Sargent et al., 1999), and this may also be the case in crustacean larvae. 
The findings of starvation studies can be used to determine the nutrients most critical as energy reserves and those catabolised or conserved in the face of increasing food deprivation. This approach has been useful with larvae of teleost fish (Takeuchi and Watanabe, 1982) and penaeid prawns (D'Souza, 1998). However, the broodstock contribution to the newly-hatched larvae via the egg may significantly influence the profile of these nutritional parameters at, and soon after, hatch and so it is important to examine the later larval stages when the broodstock contribution to the developing larvae is negligible. This study investigated the effects of feeding and starvation on the compositional changes in phyllosoma up to Stage VI of larval development. The implications that are drawn from this will assist in formulating suitable diets for spiny lobster larvae.

\section{Materials and methods}

Capture and care of broodstock, collection and handling of larvae

Ovigerous spiny lobsters $(n=3)$ weighing 500-700 g were collected from the west coast of Tasmania near Port Davey in July 2000 and transported to the Marine Research Laboratories, Taroona where they were held at ambient water temperatures $\left(9.5-14.5^{\circ} \mathrm{C}\right)$ until egg hatch in late September. Newly-hatched phyllosoma were skimmed from near the water surface of broodstock holding tanks and transferred to 251 buckets where they were disinfected with $25 \mathrm{ppm}$ formaldehyde in sea water for $30 \mathrm{~min}$. The disinfected larvae were rinsed in clean sea water and counted into each culture vessel $\left(1,000\right.$ vessel $\left.^{-1}\right)$.

\section{Larval culture}

The system for culture of phyllosoma was described previously (Ritar, 2001). Briefly, sea water was filtered to $1 \mu \mathrm{m}$, heated to $18^{\circ} \mathrm{C}$ and disinfected with ultraviolet irradiation before entering circular 351 plastic vessels. Water was jetted through four equally-spaced nozzles positioned near the bottom perimeter of the vessel and another two towards the bottom centre of the vessel to provide a circular flow to assist phyllosoma movement through the water column. Water flow to each vessel was adjusted to at least $600 \mathrm{ml} \mathrm{min}^{-1}$ and the volume was maintained at a constant 101 with excess water exiting through a screen positioned on the wall of the vessel. There was partial recirculation of water through the entire system at a rate of approximately six complete exchanges daily. Phyllosoma were fed a daily ration of 3 Artemia $\mathrm{ml}^{-1}$ from hatch. Artemia remaining from the previous day's ration were flushed from the culture vessels for $4 \mathrm{~h}$ prior to feeding the next daily ration of recently enriched Artemia. Phyllosoma were transferred to clean vessels weekly (by pouring) after uneaten food and debris were removed from the dirty vessels. For larvae starved during Stages II (from day 12 after hatch for 6 days), IV (from day 34 after hatch for 6 days), and VI (from day 63 after hatch for 11 days), culture vessels received the same daily husbandry routine except that no Artemia were fed. Samples of larvae from Stages II and IV continued to be starved until 100\% mortality was recorded. All Stage VI larvae at day 74 after hatch were required for lipid analysis.

\section{Artemia production}

Artemia cysts (E.G. grade, Artemia Systems, INVE, Belgium) were hatched daily in 50 1 conical tanks at $28^{\circ} \mathrm{C}$ in $1 \mu \mathrm{m}$ filtered sea water. The nauplii were grown on blended brine shrimp food (consisting of rice pollard, soyflour and wheat flour; Eyre Peninsula Aquafeeds Pty Ltd, South Australia) to approximately $1.5 \mathrm{~mm}$ (5 days old). 
Preliminary investigations examined the effects of several Artemia diets fed to $J$. edwardsii phyllosoma to the end of Stage II and found that larval survival and growth were highest when fed Artemia enriched with the diatom alga Chaetoceros muelleri and DHA Selco (INVE, Belgium). Therefore, in this study, Artemia were enriched for $6 \mathrm{~h}$ in separate 501 conical tanks with C. muelleri or DHA Selco. Artemia enriched with C. muelleri or DHA Selco were combined at a ratio of 2:1. Artemia were washed to remove debris and disinfected for at least $10 \mathrm{~min}$ in $100 \mathrm{ppm}$ formaldehyde before feeding to phyllosoma.

\section{Determination of moults, mortalities and larval sizes}

Larval exuviae and mortalities were removed and counted daily. Mortalities were confirmed by counting all survivors approximately 5 days after the peak of moulting at each stage. At this time, a sample $(\mathrm{n}=15)$ of larvae from each culture vessel was measured for body length (from the anterior tip of the cephalic shield between the eyestalks to the posterior tip of the abdomen) and width (left and right extremes of the cephalic shield) on a Nikon 6C Profile Projector (Japan) before returning to the culture vessel. Stages of larval development were determined according to Lesser (1978). On day 54 after hatch, fed larvae at Stage V and starved larvae still at Stage IV (i.e. starved since day 34) were examined for contamination of Vibrio spp. on thiosulphate citrate bile salt agar plates.

\section{Analysis of samples for dry weight, proximate composition and ascorbic acid}

The number of phyllosoma collected in triplicate for analyses within each stage for fed and starved treatments is shown in Table 1. The low number of phyllosoma still available at Stage VI only allowed for analyses of lipid classes and fatty acids. Samples of enriched Artemia (as well as C. muelleri and DHA Selco enrichments) were collected at regular intervals during the experiment. Samples were rinsed in $0.5 \mathrm{M}$ ammonium formate and immediately frozen in liquid nitrogen before transfer to a $-70^{\circ} \mathrm{C}$ freezer. Samples were freeze dried to determine dry weight $(\mathrm{dw})$ immediately prior to analysis.

Protein was analysed by homogenising $5 \mathrm{mg}$ freeze-dried samples in $0.37 \mathrm{~mol} \mathrm{l}^{-1}$ trichloroacetic acid using a modified Lowry et al. technique (Clayton et al., 1988). For carbohydrate analysis, $5 \mathrm{mg}$ freeze-dried samples were hydrolysed in $4 \mathrm{ml}$ of $0.5 \mathrm{~mol}^{-1}$ sulphuric acid at $100^{\circ} \mathrm{C}$ for $4 \mathrm{~h}$ in polypropylene centrifuge tubes following the phenolsulphuric acid method (Dubois et al., 1956).

Lipids were extracted using a modification of the Bligh and Dyer (1959) method from freeze-dried material according to Dunstan et al. (1993). Lipid extracts were stored at $20^{\circ} \mathrm{C}$ under nitrogen prior to analysis. The amount of lipid was determined gravimetrically using a Mettler AE 163 digital balance. An aliquot of each lipid extract was transesterified with a methanolic hydrochloric acid solution to form fatty acid methyl esters according to Christie (1982) as per Dunstan et al. (1993). The fatty acid methyl esters samples were analysed with a HP5890A gas chromatograph equipped with a flame ionisation detector and SGE OCI-3 on-column injector. A polar 70\% cyanopropyl siloxane (BP-X70) fusedsilica capillary column ( $50 \mathrm{~m}$ x $0.25 \mathrm{~mm}$ i.d.) (SGE, Australia) was used. Samples were injected at $45^{\circ} \mathrm{C}$, and after $1 \mathrm{~min}$ the oven temperature was raised to $120^{\circ} \mathrm{C}$ at $30^{\circ} \mathrm{C}$ per min and then to $245^{\circ} \mathrm{C}$ at $3^{\circ} \mathrm{C}$ per min. The final temperature was maintained for $20 \mathrm{~min}$. Helium was used as the carrier gas. The detector temperature was $260^{\circ} \mathrm{C}$. Peak areas were quantified with Millennium software.

Ascorbic acid (AsA) was analysed from freeze-dried samples $(50-100 \mathrm{mg})$ by the method of Brown et al. (1998). In brief, this required homogenising and extracting the samples with a $0.38 \mathrm{~mol}^{-1}$ metaphosphoric acid / $1.33 \mathrm{~mol}^{-1}$ acetic acid solution with 
conversion of the extracted AsA to a fluourescent derivative and analysis by high performance liquid chromatography.

\section{Statistical analysis and abbreviations}

Statistical analyses were conducted using one-way analyses of variance and TukeyKramer HSD tests for post-hoc multiple comparisons. After $\arcsin \sqrt{ }$ transformations were performed, survival data were normal and homogeneous (Sokal and Rohlf, 1995). The level of significance for all analyses was $\mathrm{P}<0.05$. Statistical analyses were performed using JMP version 5.0 (SAS Institute Inc.). Data are presented as mean \pm standard error.

Abbreviations used repeatedly in the text are: ARA, arachidonic acid (20:4n-6); AsA, ascorbic acid; DG, diacylglycerol; DHA, docosahexaenoic acid (22:6n-3); dw, dry weight; EFA, essential fatty acid; EPA, eicosapentaenoic acid (20:5n-3); FA, fatty acid; FFA, free fatty acid; MUFA, monounsaturated fatty acid; PL, polar lipid; PUFA, polyunsaturated fatty acid; SFA, saturated fatty acid; ST, sterol; TAG, triacylglycerol; WE, wax ester.

\section{Results}

\section{Phyllosoma growth and survival to Stage VI}

Body lengths and widths of newly-hatched phyllosoma larvae were $2.06 \pm 0.01 \mathrm{~mm}$ and $1.21 \pm 0.01 \mathrm{~mm}$, respectively, and increased at each stage to Stage VI in increments of approximately $1.0 \mathrm{~mm}$ and $0.6 \mathrm{~mm}$ (Fig. 1). Early larval survival was high; the survivals from hatch to days 8 and 18 (just prior to the moult to Stages II and III) were $90.8 \pm 3.3 \%$ and $89.3 \pm 2.0 \%$, respectively. Survival then declined to $57.7 \pm 8.4 \%$ on day 25 (mid-way through Stage III). On days 40, 50 and 63, survivals were $37.0 \pm 7.5 \%, 25.2 \pm 5.6 \%$ and $10.1 \pm 4.1 \%$, respectively. During the periods of starvation at Stages II, IV and VI (i.e. from day 12 for 6 days, day 34 for 6 days, and day 63 for 11 days, respectively), the survivals were not significantly different for larvae which were starved or fed.

For larvae at Stage II and Stage IV which continued to be starved, 50\% mortalities occurred on approximately days 27 and 57 after hatch, respectively, i.e. 15 and 23 days after the start of starvation (Fig. 2). All starved Stage II and IV larvae were dead by days 32 and 65 after hatch, respectively. No starved larvae at Stages II and IV moulted to the next stage.

\section{Dry weight, protein, lipid and carbohydrate content of phyllosoma and enriched Artemia}

The average dw of each phyllosoma increased from $80 \mu \mathrm{g}$ at hatch to $1,415 \mu \mathrm{g}$ at the end of Stage VI (Table 1 and Fig. 3a). The dw at the end of Stages II, IV and VI was lower for starved than fed phyllosoma by $40 \%, 14 \%$ and $35 \%$, respectively. Within stages, the $\mathrm{dw}$ of protein, lipid and carbohydrate generally increased for fed larvae but declined for starved larvae. The exception was for fed phyllosoma during Stage IV, which showed no change for lipid and carbohydrate content. Unfortunately, there were insufficient larvae to analyze protein and carbohydrate content at Stage VI.

The amount of protein in newly-hatched phyllosoma was $25 \pm 2 \mu \mathrm{g}_{\text {phyllosoma }}{ }^{-1}$ and increased to $42 \pm 3 \mu \mathrm{g}$ phyllosoma ${ }^{-1}$ by the end of Stage I (Fig. 3b), which accounted for $31 \%$ and $34 \%$ of the total dw, respectively (Table 1). Protein dw in fed phyllosoma at the end of Stages II and IV were $148 \pm 6$ and $322 \pm 1 \mu \mathrm{g}$ phyllosoma ${ }^{-1}$, which accounted for $38 \%$ and $42 \%$ of the total dw, respectively. At the end of starvation of Stages II and IV, the protein dws were $79 \pm 4$ and $239 \pm 3 \mu$ g phyllosoma $^{-1}$, which were $46 \%$ and $26 \%$, respectively, less than for fed phyllosoma. In proportional terms, protein content of 
phyllosoma ranged from $31 \%$ at hatch to a high of $42 \%$ for fed larvae at Stage IV, and increased within stage during feeding only at Stage II (Table 1).

The amount of lipid increased from 6 to $20 \mu \mathrm{g}_{\text {phyllosoma }}{ }^{-1}$ from hatch to the end of Stage I and at the end of Stages II, IV and VI reached 31, 77 and $134 \mu$ phyllosoma $^{-1}$ for fed larvae (Fig. 3c). Lipid dw declined during starvation to the end of Stages II, IV and VI to 6,45 and $36 \mu$ g phyllosoma ${ }^{-1}$ (i.e. reduced by $81 \%, 41 \%$ and $73 \%$ compared to fed larvae), respectively. Proportionally, lipid content at hatch was $7.4 \%$ of larval dw (Table 1) and was higher subsequently for fed larvae reaching a peak of $12.5 \%$ at Stage IV on day 34 , while there was a marked decrease during starvation at Stages II, IV and VI (to 3.9\%, $7.1 \%$ and $3.9 \%$ ).

The lipid:protein ratio for newly-hatched phyllosoma was 0.24 and doubled to 0.48 on day 8 shortly before moult to Stage II, reflecting a more rapid accumulation of lipid than protein (Fig. 3d). The lipid:protein ratio of early Stage II (0.21) and early Stage IV (0.31) larvae was similar to newly-hatched larvae. In fed phyllosoma, there was a rise in this ratio during mid-Stage II (0.30) before again declining just before moult to Stage III $(0.21)$ suggesting a change in the rate of accumulation of lipid and protein. By contrast, there was a continuous decline in this ratio during Stage II in starved larvae to a low of 0.08 , suggesting that the rate of lipid catabolism was greater than that of protein. However, by Stage IV, the lipid:protein ratios declined in both fed and starved larvae to lows of 0.24 and 0.19 , but for different reasons. At Stage IV, fed larvae showed no change in lipid content while there was a small rise in protein content by the end of the stage, whereas in starved larvae the decline in lipid content was more rapid than for protein.

The amount of carbohydrate in newly-hatched phyllosoma was $2.4 \pm 0.2 \mu \mathrm{g}$ phyllosoma $^{-1}$ and increased to $9.7 \pm 0.6 \mu$ phyllosoma $^{-1}$ by the end of Stage I (Fig. 3e), which accounted for $3.0 \%$ and $5.3 \%$ of the total dw, respectively. The carbohydrate dw in fed phyllosoma at the end of Stages II and IV were $14 \pm 1$ and $20 \pm 4 \mu$ phyllosoma $^{-1}$, which accounted for $3.6 \%$ and $2.7 \%$ of the total dw, respectively. At the end of starvation of Stages II and IV, the carbohydrate content was lower by $43 \%$ and $18 \%$, respectively, than for fed phyllosoma. Proportionally, carbohydrate content increased after hatch to day 8 but thereafter there was no clear pattern of change in the proportional content of carbohydrate between or within stages for fed or starved phyllosoma.

The protein content was lower but the lipid content was higher for Artemia (1.61 \pm 0.15 mm long) after enrichment with DHA Selco compared with C. muelleri, while carbohydrate content was similar (Table 1). Thus, the contents of protein, lipid and carbohydrate following combination of Artemia enriched with the two products $(2: 1, C$. muelleri:DHA Selco enrichment) were $38.3 \%, 13.6 \%$ and $10.6 \%$, respectively. The lipid contents of C. muelleri and DHA Selco were $4.5 \pm 0.5 \%$ and $79.2 \pm 6.0 \%$ of dw, respectively.

\section{Lipid classes and fatty acids}

Polar lipid (PL) was the major lipid class, constituting 79-92\% of total lipid, and ranging in concentrations from a low of $28 \mathrm{mg} \mathrm{g}^{-1} \mathrm{dw}$ in starved phyllosoma at day 74 (Stage VI) to a high of $107 \mathrm{mg} \mathrm{g}^{-1} \mathrm{dw}$ in fed phyllosoma at day 34 (Stage IV) (Fig. 4). PL was the only lipid class significantly reduced during starvation with PL content $45 \%, 38 \%$ and $70 \%$ less for starved than for fed larvae at the end of Stages II, IV and VI, respectively. The next most abundant lipid class in phyllosoma was sterol (ST), accounting for $5.8-20.1 \%$ of total lipids and was the only lipid class conserved during starvation at all stages. Diacylglycerols (DG), wax esters (WE), triacylglycerols (TAG) and free fatty acids (FFA) were detected in low proportions (each $\leq 2 \%$ ) and none of which showed 
significant changes with stage of development or with starvation. For enriched Artemia, TAG content was considerably higher after enrichment with DHA Selco than with $C$. muelleri (66 and $38 \mathrm{mg} \mathrm{g}^{-1} \mathrm{dw}$, respectively) while the other lipid classes were also generally slightly higher for Artemia enriched with DHA Selco than C. muelleri (PL: 58 and 57; ST: 7 and 6; FFA: 5 and 2; WE: 0.7 and 0.7; DG: 0.2 and $0.1 \mathrm{mg} \mathrm{g}^{-1} \mathrm{dw}$ ) (Fig. 4).

Fatty acids (FA) constituted 52.7-77.1\% of total lipid and this proportion did not appear to show any clear pattern of change between stages of development or for feeding and starvation. However, the amount of FA increased with the stage of development and within stage for fed phyllosoma and decreased with starvation in a similar pattern to total lipid content (Table 1). FA content increased more than 3-fold within Stage I (from hatch to day 8 ) and by $24-$ fold to Stage VI (at day 74) but was $42 \%, 67 \%$ and $69 \%$ less for starved than fed phyllosoma at the end of Stages II, IV and VI, respectively. The content of most individual FA increased between and within stages during feeding, and all FA decreased during starvation (data not shown).

Of the 51 individual FA identified in the analyses of phyllosoma samples, 16 were at concentrations of $\geq 1 \%$ of the total lipid at hatch or up to Stage VI (Table 2). The five most abundant FA in newly-hatched phyllosoma were EPA $(20: 5 n-3 ; 17.1 \%), 16: 0$ (13.9\%), $18: 1 n-9(12.3 \%)$, DHA $(22: 6 n-3 ; 10.7 \%)$ and ARA $(20: 4 n-6 ; 7.0 \%)$. Toward the end of Stage I after 8 days of feeding on enriched Artemia, the five most abundant FA were 18:1n-9 (19.3\%), 16:0 (12.2\%), 18:2n-6 (11.3\%), EPA (11.0\%) and 18:0 (8.8\%), while DHA and ARA had reduced to $3.7 \%$ and $3.2 \%$, respectively. By the end of Stage VI for fed phyllosoma, the content of EPA was $9.5 \%$, DHA was $2.8 \%$, and ARA was $3.2 \%$, while 16:0 reduced to $10.8 \%$. 18:1n-9 and 18:2n-6 became the most abundant FA by day 8 in fed larvae and by the end of Stage VI had increased to $25.3 \%$ and $18.7 \%$, respectively, while their loss during starvation was greater than for other FA. The proportions of EFA (DHA, EPA and ARA) declined markedly in fed phyllosoma between hatch and day 8. In subsequent stages, the contribution of EFA to the total lipid remained steady or fell slightly for fed phyllosoma but increased proportionally in starved larvae, with these changes generally reflected in the sum of PUFA. The DHA:EPA:ARA ratios changed from hatch at 10:16:7 to 10:30:9 at day 8 with a relative doubling of EPA and a slight increase in ARA, although this actually reflected the large reduction in DHA by comparison to the smaller reductions in EPA and ARA. The ratios then remained steady to Stage VI.

In quantitative terms, the increase in FA in fed larvae from hatch to Stage VI at day 74, in order of magnitude, was highest for 18:1n-9, followed by 18:2n-6, 16:0, EPA, 18:1n-7, ARA and DHA (Fig. 5). All the EFA decreased during starvation, as did 16:0, 18:0, 18:1n7, 18:1n-9 and 18:2n-6. These FA were between 14-80\% lower for starved than fed larvae at the end of Stages II, IV and VI.

The \% sum of saturated fatty acids (SFA) mostly remained stable throughout development (Table 2). However, stearic acid 18:0 increased somewhat after hatch and was the second most abundant SFA after palmitic acid 16:0, and both remained unchanged or declined slightly between and within stages during feeding whereas they were conserved during periods of starvation. By contrast, the \% sum of monounsaturated fatty acids (MUFA) increased from $28.3 \%$ to $36.3 \%$ from hatch to day 8 and then remained elevated between and within stages for fed phyllosoma, but were catabolised during periods of starvation so that phyllosoma at the end of Stages II, IV and VI contained $8.1 \%$, $3.7 \%$ and $6.1 \%$ less MUFA than their fed counterparts. The $\%$ sum PUFA declined from hatch to day 8 from $44.0 \%$ to $37.7 \%$ and remained near this level between and within stages for fed phyllosoma but either increased by 1.2\%-5.5\% for Stages II and VI or did not change for Stage IV phyllosoma during starvation. 
From hatch to day 8 , the $\%$ sum n-3 FA decreased from $30.0 \%$ to $19.4 \%$ while the $\%$ sum n-6 increased from $11.1 \%$ to $17.2 \%$. The content of n-3 FA continued to decline, so that by the end of Stage VI for fed phyllosoma, it was only $14.0 \%$. On the other hand, the content of n- 6 continued to increase and reached its peak in fed phyllosoma at the end of Stage VI (25.2\%). Thus, the n-3:n-6 ratio decreased from 2.7 at hatch to 0.6 at the end of Stage VI for fed phyllosoma. During periods of starvation, the slight increase in $n-3$ and decrease in $n-6$ resulted in a slight increase in the n-3:n-6 ratio compared with fed counterparts.

The FA profile (\% of total FA) of enriched Artemia (combined 2:1) was distinct from newly-hatched phyllosoma, and was dominated by $\mathrm{C}_{18}$ fatty acids, principally $18: 1 \mathrm{n}-9$ (28.6\%) and 18:2n-6 (22.4\%), with other FAs at concentrations of $<10 \%$ and generally less abundant in Artemia compared with any phyllosoma samples. EPA, DHA and ARA were present at 5.4\%, 2.7\% and $1.4 \%$, respectively. The concentrations in the enrichments $C$. muelleri and DHA Selco of DHA (1.0\% and $21.0 \%)$ and ARA (1.6\% and $1.7 \%)$, but not of EPA (20.4\% and 5.2\%), were reflected in the Artemia enriched with these different products. The changes in FA composition of fed phyllosoma between and within stages did not consistently reflect the composition of enriched Artemia. ARA and EPA were both proportionally much higher, while DHA was similar, in fed phyllosoma compared with Artemia. The content of 18:1n-9 and 18:2n-6 in fed phyllosoma progressively increased in later stages to reflect enriched Artemia.

\section{Ascorbic acid}

Ascorbic acid content at hatch was $2.9 \pm 0.1 \mathrm{ng}^{\text {phyllosoma }}{ }^{-1}$, increasing to $61 \pm 3 \mathrm{ng}$ phyllosoma ${ }^{-1}$ by day 8 after hatch. Stage II larvae contained $35 \pm 2 \mathrm{ng}$ phyllosoma $^{-1}$ at day 12 , remaining at $40 \pm 6 \mathrm{ng}$ phyllosoma ${ }^{-1}$ at day 18 with starvation while increasing to $169 \pm$ 10 ng phyllosoma ${ }^{-1}$ with feeding. Subsequent stages were not analysed because of insufficient animals. On a dw basis, concentrations at hatch, day 8 and day 12 were $36 \pm 2$, $333 \pm 19$ and $156 \pm 11 \mu \mathrm{g} \mathrm{g}^{-1}$, whereas fed and starved larvae at day 18 were $439 \pm 33$ and $174 \pm 29 \mu \mathrm{g} \mathrm{g}^{-1}$.

\section{Microbiology}

When sampled on day 54 after hatch, fed Stage V larvae had continuing high mortalities whereas starved Stage IV larvae had low mortalities. Fed larvae had light to heavy external fouling around the head and eyes, melanisation at the junction of the carapace and appendages associated with clusters of motile protozoa, granulomas in the haemolymph space and in the eyes, moderate to heavy occurrence of Leucothrix-like bacteria over the setae and terminal appendages, and occasional stalked sessile ciliates attached to the body. Starved larvae generally contained slightly less fouling than the fed larvae, and there were fewer haemocytes, their circulation was slower and the heart beat was weak, which was associated with weaker swimming activity as many larvae were approaching death due to starvation. Histopathology showed that digestive tubule integrity was variable with sloughing of gut cells in both fed and starved larvae. The microbiological loads of Vibrio spp. were greater $(\mathrm{P}<0.05)$ in the fed than the starved larvae $(6,370 \pm 1,500$ and $2,220 \pm 50$ cfu phyllosoma $^{-1}$ ). The predominant flora associated with both fed and starved phyllosoma was Vibrio splendidus, which is an opportunistic pathogen commonly associated with aquatic animals.

\section{Discussion}


The nutritional requirements of spiny lobster phyllosoma are largely unknown. In the wild, it is likely that larvae consume a broad spectrum of zooplankton, which varies with season and location. However, for phyllosoma culture, Artemia is presently the diet of choice because it is simple to prepare, seems attractive to larvae and has been used as the principal or sole component during the long larval phase through metamorphosis to puerulus (Kittaka, 1994; Moss et al., 2000). Our recent studies (Ritar et al., 2002; 2003) indicated that it is preferable to feed live Artemia rather than inert diets (shellfish or formulated) or in combination with other feeds such as mussel flesh. The possible introduction of high microbial loadings via infected Artemia, which sometimes leads to complete mortality (unpublished data; G. Moss, pers. comm.) was addressed in the current study by disinfection of the Artemia (Ritar, 2001). Protein:energy ratios and low levels of PUFA in Artemia can be readily adjusted by enrichment with suitable diets (Nelson et al., 2002; Smith et al., 2002). Growth (or intermoult interval) of J. edwardsii phyllosoma is faster in culture, partly a reflection of the higher temperature $\left(18^{\circ} \mathrm{C}\right)$ than in the wild, but may be diet related as growth is elevated for phyllosoma fed Artemia compared to other diets (unpublished data; G. Moss, pers. comm.).

The growth (body lengths and widths) and survival of cultured phyllosomas in this study were similar to those found previously (Tong et al., 1997; Ritar, 2001; Ritar et al., 2002, 2003). By the end of Stage VI, larval dw had increased 17-fold from hatch. Larval survival was initially high during Stages I and II while the subsequent continuous mortality resulted in less than $10 \%$ of larvae still alive by the end of Stage VI, which is somewhat lower than found previously in this species when fed an Artemia-only diet (Illingworth et al., 1997; Ritar, 2001). Survival can vary considerably between experiments when using flow-through or recirculating culture systems probably due to the incidence of microbial infections (Handlinger et al., 2001). In addition, the mortalities during the short period of starvation at Stages II (for 6 days), IV (for 6 days) and VI (for 11 days) in this study were similar to or lower than for fed larvae, which is probably due to the lower bacterial abundance in the system since no microbial-laden Artemia were fed to these animals. One of the consequences of these infections is a reduction in the functional integrity of the larval digestive tract (Johnston and Ritar, 2001), rather than poor nutritional quality of the Artemia diet. In contrast, high larval survival $(>50 \%)$ to Stage V was obtained during Artemia feeding in static cultures containing antibiotics (Nelson et al., 2003; Smith et al., 2003b).

Larvae exhibited 50\% mortality 15 and 23 days after commencing starvation at Stages II and IV, respectively. This reflects the high level of energy reserves which animals mobilized for survival when held at culture temperatures of $18^{\circ} \mathrm{C}$. Nevertheless, it was likely that the extended starvation was well beyond their point-of-no-return, which for early Stage I phyllosoma was only 4 days (Abrunhosa and Kittaka, 1997). For starved larvae at Stages II, IV and VI, the reserves were insufficient to permit moulting to the next stage, whereas the intermoult interval for these early larval stages is normally just 10-12 days when fed an Artemia diet (Tong et al., 1997; Ritar et al., 2002).

The increase of $127 \%$ in dry weight within Stage I from hatch to day 8 during feeding was much greater than the $17 \%$ found previously (Smith et al., $2003 \mathrm{c}$ ), and higher also than during feeding for 6-11 days within Stages II (72\%), IV (6\%) and VI (32\%). Conversely, the $44 \%$ loss in dw during starvation of Stage I phyllosoma in the previously mentioned study was greater than the highest loss of 15\% (at Stage VI) observed here. The high loss at Stage I included the depletion of the large yolk content present at hatch.

In fed larvae, protein constituted the largest proportion of the dry mass (31.4-41.7\%), followed by lipid (7.4-12.5\%), with carbohydrate occupying only a minor component (2.7- 
$5.3 \%$ ). The relative proportions of protein, lipid and carbohydrate were similar to those observed previously in cultured and wild-caught larvae (Phleger et al., 2001; Ritar et al., 2003; Smith et al., 2003 c). The overall increase in dry weight of fed phyllosoma was generally accompanied by increases in the absolute amount of all these components, while the considerable loss in body mass during starvation for 6-11 days at Stages II, IV and VI was characterized by depletion in all these components. Neither chitin nor ash, which can represent more than $30 \%$ of body components, were analysed because of insufficient quantity of tissue sample. Chitin normally represents up to $15 \%$ of biomass in decapod crustaceans (Anger, 2001), while ash may constitute up to 28\% of dw (Brown et al., 2001; Ritar et al., 2003).

Protein requirements of crustacean larvae remain relatively unchanged during development (Teshima et al., 1986; Roustaian et al., 2000) and can be satisfied by a suitable protein source that resembles the amino acid profile of larvae. For fed phyllosoma, more protein was accumulated than other components within and between stages, while more protein was lost during starvation than other components to meet the energy requirements of starved phyllosoma which is similar to other decapods (Anger, 2001).

For newly-hatched larvae, the lipid content was within the $7-12 \%$ range typically found in J. edwardsii (Phleger et al., 2001; Smith et al., 2003 a; 2003 c). The lipid content in fed larvae remained within this range during development but declined markedly during starvation. We found that the loss in lipid encountered during starvation within Stages II, IV and VI was 41-81\%, whereas the loss in dw due to lipid catabolism during starvation of Stage I larvae to day 8 after hatch was previously found to be only 18\% (Smith et al., 2003 c). This suggests that lipid catabolism is a more important source of energy for the later stages of development, whereas protein catabolism may be more important in Stage I.

Roustaian et al. (2001) also suggested that the decline in lipid content at later stages of Macrobrachium rosenbergii larval development was attributable to it being utilized as the major metabolic source of energy.

The marked increase in the lipid:protein ratio with feeding during Stage I shows that there is a more rapid accumulation of lipid than protein. The minor changes in the lipid:protein ratio for fed phyllosoma at subsequent stages indicates that lipid and protein are accumulated at similar rates between moults. On the other hand, the rapid reduction in lipid:protein during starvation at Stages II and IV shows that lipid is mobilized sooner and faster than protein for maintenance of vital functions. For larvae enduring starvation beyond day 18 at Stage II and day 40 at Stage IV, the depletion of energy from protein and lipid catabolism would have contributed substantially to the functional maintenance of phyllosoma (Abrunhosa and Kittaka, 1997; Anger, 2001) even though this was probably well beyond their point-of-no-return.

Free carbohydrate, in the form of glucose, plays a key role in energy metabolism (Anger, 2001). It also has a rapid turnover, so its content is low compared to protein and lipid and typically constitutes less than $5 \%$ of body mass. The degradation of lipids (and proteins to a lesser extent) increases the concentration of free carbohydrates. In quantitative terms, carbohydrate was accumulated within and between stages for fed larvae but lost during starvation, whereas there were no clear changes in proportional terms.

The accumulation of lipid with feeding within Stage I was principally in the form of PL, while in quantitative and proportional terms, PL showed the largest reduction during starvation, suggesting that it is the lipid class mobilised most readily for energy reserves. This agrees with previous studies which found that PL was by far the most abundant lipid class in J. edwardsii phyllosoma, typically constituting more than $80 \%$ of total lipids (Phleger et al., 2001; Smith et al., 2002; 2003 a). ST is the next most abundant lipid class (up to $20 \%$ ), followed by the other lipid classes at less than $2 \%$ each. The primary function 
of PL and ST in most marine organisms is as membrane structural lipids (Pond and Sargent, 1998). However, Phleger et al. (2001) speculated that PL is utilized as the major lipid class in phyllosoma because it offers transparency and therefore protection from predation during their long larval development in the plankton, as is the case for the puerulus (Jeffs et al., 2001). ST, comprising mainly cholesterol, is essential for normal development including as the precursors for hormones of ecdysis (D'Abramo et al., 1984) and is principally derived from the diet (Teshima and Kanazawa, 1971). TAG is the prevalent short-term lipid reserve mobilized for energy requirements in many marine organisms, with WE regarded as a long-term lipid energy reserve (Benson and Lee, 1975). However, TAG and WE represented only small proportions of the total lipids in phyllosoma in this study. Although the Artemia diet contained a substantially different balance of lipid classes (52\% PL, 40\% TAG) to newly-hatched phyllosoma, it appeared that developing larvae adequately obtained their requirements. The high TAG content in Artemia had surprisingly little effect on phyllosoma lipid composition which consistently remained at less than $1 \% \mathrm{TAG}$.

During the first 8 days of culture, the fatty acid profile of fed phyllosoma underwent large changes, subsequently changing only gradually to Stage VI, mostly reflecting the profile of the Artemia diet. The exceptions to this were 18:0, 16:1n-7 and 20:2n-6, which are possible intermediates in FA metabolism, as well as ARA and EPA, which remained at approximately twice the level of inclusion in the diet. For ARA, EPA and DHA, there was generally a quantitative increase within and between stages. However, the percentage content of all EFAs declined from hatch to day 8 but then generally remained unchanged within and between stages for fed larvae, while starved larvae showed an increase in the relative proportion of ARA, EPA and DHA, suggesting they were spared. Smith et al. (2003 c) found for Stage I J. edwardsii phyllosoma, DHA decreased quantitatively during both starvation and feeding, while the relative proportions of ARA, EPA and DHA did not differ significantly for starved larvae between hatch and day 8 . They also found that total FA content declined from hatch to day 8 of starvation (from $7.0 \%$ to $4.4 \% \mathrm{dw}$ ) and increased during feeding (to $13.0 \% \mathrm{dw}$ ), while the proportions of ARA, EPA and DHA were not significantly different in newly-hatched and starved phyllosoma but were lower in fed animals. A notable feature in the present study is the FA profile of starved Stage VI larvae at day 74 which was remarkably similar to fed Stage I at day 8.

Enrichment of Artemia with DHA Selco resulted in considerably higher lipid content than when enriched with C. muelleri (17.4\% and $11.6 \%$ of dw, respectively), as was the case for DHA content ( $7.0 \%$ and $0.5 \%$ of total fatty acids, respectively), whereas there were no substantial differences in ARA or EPA content. The combined Artemia after enrichment with $C$. muelleri or DHA Selco at 2:1 provided phyllosoma with a diet high in lipid, and containing the essential omega-3 PUFA. The final ratio of DHA:EPA:ARA of the combined Artemia emulated newly-hatched phyllosoma, which may be desirable for long-term culture. The profile of EFAs in Artemia, lower than in newly-hatched phyllosoma, resulted in consequential reductions of these components in the phyllosoma within the first 8 days but then not substantially thereafter. Conversely, 18:1n-9 and 18:2n6 , which were low in newly-hatched phyllosoma but increased markedly within 8 days of hatch and remained elevated thereafter, were high in Artemia. The 18:1n-9 and 18:2n-6 in Artemia were readily catabolised by phyllosoma during starvation, resulting in large quantitative and proportional reductions.

The fatty acid composition of J. edwardsii phyllosoma at hatch is likely to be affected by the diet fed to broodstock during gametogenesis, as is the case in other marine crustaceans (Clarke, 1982; Harrison, 1990; 1997; Roustaian et al., 1999). In this study, broodstock were obtained from the wild after egg extrusion and it was not possible to 
analyse the dietary intake. The diet probably consisted of organisms such as chitons, sea urchins and crabs which are high in PUFA (Edmunds, 1995). Some PUFA, originally derived from phytoplankton, benthic plankton and macrophytes, are incorporated unchanged into neutral and polar lipids in crustaceans, while others are converted to EPA and DHA through chain elongation and desaturation (Sargent and Whittle, 1981). The increase in ARA, EPA and DHA during larval development in $P$. japonicus (Teshima and Kanazawa, 1982) and M. rosenbergii (Roustaian et al., 1999), respectively, was accompanied by simultaneous decreases in SFA and MUFA. EPA and DHA are superior to $\mathrm{C}_{18}$ PUFA in maintaining growth in other crustaceans, such as $P$. japonicus (Kanazawa et al., 1977), which may also be the case for J. edwardsii. Marine fish (and possibly crustaceans) appear unable to elongate shorter chain PUFA to EPA and DHA at significant rates, and must therefore obtain them through their diet.

ARA is a precursor to the 2-series prostaglandins, which in adult penaeid prawns appear to be linked to moulting (development) (Koskela et al., 1992). It is therefore possible that higher levels of ARA may help to accelerate larval development. Feeding C. muelleri, which was high in ARA, resulted in elevated levels of ARA in prawn larvae as well as higher survival and growth rates compared with algae low in ARA (D'Souza and Loneragan, 1999). We previously found that the highest survival and growth occurred in phyllosoma larvae fed Artemia enriched with C. muelleri compared to other algal and oil emulsion enrichments (unpublished data). The concentration of ARA was highest in newly-hatched larvae at 7.0\%, which was similar to recent studies (Phleger et al., 2001), and remained at 3.1-5.3\% thereafter. Sargent and Whittle (1981) highlighted that $n-6$ PUFA, especially ARA, derived from the benthic algae eaten by crustaceans, are low in pelagic decapods. This is also the pattern in spiny lobsters where the adult broodstock eventually translocate the ARA from their benthic diet to the eggs and subsequently to the newly-hatched larvae. After hatch, pelagic larvae feed on organisms lower in n-6 FA.

The content of n-3 and n- 6 FAs constituted $41 \%$ of total FA in newly-hatched phyllosoma, a proportion that remained approximately stable throughout development, regardless of whether larvae were fed or starved, and was similar to the Artemia diet. However, the ratio of n-3:n-6 changed markedly from 2.7 at hatch to 1.1 after feeding of Artemia for 8 days, and further reduced to $0.6-0.8$ for larvae at Stage VI, reflecting the low ratio in Artemia. The composition of newly-hatched larvae, due to parental contribution, was therefore short-lived and did not appear to persist beyond early Stage I. For enriched Artemia (2:1), the DHA content was only $2.7 \%$ resulting in a similarly low proportion in phyllosoma at day 8 and onwards. By contrast, the reduction in ARA and EPA during larval development was considerably less. Artemia have the ability to form EPA (20:5n-3) on algal diets lacking this FA (Sargent and Whittle, 1981) by retroconversion of DHA to EPA (Navarro et al., 1999; Evjemo et al., 2001),

Of the SFA, palmitic acid 16:0, was the most abundant at hatch (13.9\%) followed by stearic acid 18:0, $(6.9 \%)$. At later stages and with starvation, the levels of these SFA converged, so that by Stage VI, they were $10.9 \%$ and $8.0 \%$, respectively, for fed larvae. These findings are similar to those of Phleger et al. (2001) for newly-hatched larvae, although at later stages, cultured animals in this study were considerably lower in 16:0 than wild-caught phyllosoma. The MUFA, oleic acid 18:1(n-9) and its (n-7) isomer cisvaccenic acid 18:1(n-7), increased after hatch, not necessarily reflecting the concentrations in the Artemia diet because like the SFA, these can most likely be synthesized de novo by the phyllosoma.

Even as larval development proceeds, with growth and energy requirements being met by the diet, dependency on lipid stores remains steady, as exhibited by large and continuous declines during starvation in the content of lipid at a greater rate than for 
protein. All fatty acids were mobilized as energy sources, some at greater rates than others, with the EFA mobilized at a somewhat lower rate than the major SFA and MUFA. This indicates that there is a degree of preferential retention of the EFA during food deprivation, as suggested previously for Stage I phyllosoma (Smith et al., $2003 \mathrm{c}$ ).

Concentrations of ascorbic acid in phyllosoma that were fed Artemia enriched 2:1 increased by more than 10-fold from hatch $\left(36 \mu \mathrm{g} \mathrm{g}^{-1}\right)$ through to day $18\left(439 \mu \mathrm{g} \mathrm{g}^{-1}\right)$. However, concentrations decreased considerably from just before moult at day $8(333 \mu \mathrm{g}$

$\mathrm{g}^{-1}$; late stage I) to just after moult at day 12 (156 $\mathrm{g} \mathrm{g} \mathrm{g}^{-1}$; early stage II), which supports the suggestion by Dabrowski (1992) that ascorbic acid is metabolised for stressful events, such as ecdysis, creating a high demand on reserves. From day 12 up to day 18, feeding reestablished tissue concentrations of ascorbic acid to above pre-moult levels, whereas starved phyllosoma showed strong retention with no significant change in the concentration of the vitamin. The increase in ascorbate during ontogeny indicated that diets contained sufficient ascorbate to meet larval requirements. Further, Merchie et al. (1997) found that naturally occurring levels of ascorbate in Artemia $\left(550 \mu \mathrm{g} \mathrm{g}^{-1}\right)$ were sufficient to meet the requirements of freshwater prawn larvae, but they suggested that higher levels $\left(>1,400 \mu \mathrm{g} \mathrm{g}^{-1}\right)$ might improve larval stress resistance. Although we did not measure ascorbic acid in the diets, our previous studies showed that DHA Selco-fed Artemia contained $680 \mu \mathrm{g} \mathrm{g}^{-1}$, whereas Artemia enriched with microalgae (e.g. Isochrysis sp.T-Iso) contained 1,700 $\mu \mathrm{g} \mathrm{g}^{-1}$ (Ritar et al., 2003).

Artemia appear to be a most practical diet for phyllosoma, even if nutritionally incomplete, and will continue to be used until more suitable alternatives are developed. The compositional changes, which occur in phyllosoma after feeding Artemia or after starvation, provide guidance in the development of suitable dietary regimes, both for Artemia manipulation and when inert alternatives are explored. For example, there would likely be benefit in increasing the ARA, EPA and DHA content of the diet as starvation of phyllosoma has shown that it is these fatty acids which are conserved relative to the SFA and MUFA. Enrichment with algae, oil emulsions and other products offers the possibility to markedly alter the Artemia and then the phyllosoma in total lipid content, lipid class composition (especially the balance of TAG to PL), as well as the profile of fatty acids, including EFA, and ascorbic acid, to improve growth and development of phyllosoma.

\section{Acknowledgements}

We thank Craig Thomas for technical assistance and the members of the Fish Health Unit, Department of Primary Industry, Water and Environment, for the microbiological assessment of phyllosoma samples. Mina Brock assisted with the lipid analyses, and Danny Holdsworth with GC-MS management, respectively. Ross Parker's assistance in the capture of broodstock is gratefully acknowledged. This project was supported by the Fisheries Research and Development Corporation (Project number 2000/214). Dr Peter Nichols and Mr Greg Smith provided valuable comment on the draft manuscript. 


\section{References}

Abrunhosa, F.A., Kittaka, J. 1997. Effect of starvation on the first larvae of Homarus americanus (Decapoda, Nephropidae) and phyllosomas of Jasus verreauxi and $J$. edwardsii (Decapoda Palinuridae). Bulletin of Marine Science 61, 73-80.

Anger, K. 2001. The biology of decapod crustacean larvae. Swets and Zeitlinger B.V., Lisse. $420 \mathrm{pp}$.

Benson, A.A., Lee, R.F. 1975. The role of wax in oceanic food chains. Scientific American 232, 77-86.

Bligh E.G., Dyer W.F. 1959. A rapid method of total lipid extraction and purification. Canadian Journal of Biochemistry and Physiology 37, 911-917.

Booth, J.D. 1994. Jasus edwardsii larval recruitment off the east coast of New Zealand. Crustaceana 66, 295-317.

Booth, J.D., Phillips, B.F. 1994. Early life history of spiny lobster. Crustaceana 66, 271294.

Brown, M.R., Skabo, S., Wilkinson, B. 1998. The enrichment and retention of ascorbic acid in rotifers fed microalgal diets. Aquaculture Nutrition 4, 151-156.

Brown, M., Dunstan, G., Augerinos, M. 2001. Biochemistry of wild and cultured phyllosoma. In: FRDC Final Report. Rock Lobster Enhancement and Aquaculture Subprogram: The Development of Rock Lobster Propagation Techniques for Aquaculture in Australia. (Eds. B.J. Crear and P.R. Hart) (FRDC Project No. 1999/315; ISSN 1441-8487). pp. 33-37.

Cahu C., Fauvel C. 1986. Effect of food fatty acid composition of Penaeus vannamei broodstock on egg quality. International Council for the Exploration of the Sea F28, 5 pp.

Castell J.D. 1982. Fatty acid metabolism in crustaceans. In: Pruder G.D., Langdon C.J. and Conklin D.E. (Eds.) Proceedings of the Second International Conference on Aquaculture Nutrition: Biochemical and Physiological Approaches to Shellfish Nutrition, pp. 124-145. Louisiana State University Division of Continuing Education, Baton Rouge Louisiana.

Christe, W.W. 1982. Lipid Analysis. Oxford, England, Pergamon Press.

Clarke, A. 1982. Lipid synthesis and reproduction in the polar shrimp Chorismus antarcticus. Marine Ecology Progress Series 9, 81-90.

Clayton, J.R. jr., Dortch, Q., Thoreson, S.S., Ahmed, S.I. 1988. Evaluation of methods for the separation and analysis of proteins and free amino acids in phytoplankton samples. Journal of Plankton Research 10, 341-358.

D'Abramo, L. R., Bordner, C.E., Conklin, D.E., Baum, N.A. 1984. Sterol requirements of juvenile lobsters, Homarus sp. Aquaculture 42, 13-25.

D'Souza, F.M.L. 1998. The nutritional value of microalgae to penaeid prawn larvae. In: PhD Thesis, Queensland University of Technology, Brisbane. 199 pp.

D'Souza, F.M.L., Loneragan, N.R. 1999. Effects of monospecific and mixed-algae diets on survival, development and fatty acid composition of penaeid prawn (Penaeus spp.) larvae. Marine Biology 133, 621-633.

Dabrowski, K. 1992. Ascorbate concentration in fish ontogeny. Journal of Fish Biology 40, 273-279.

Deering, M.J., Fielder, D.R., Hewit, D.R. 1997. Growth and fatty acid composition of juvenile leader prawns, Peneaus monodon, fed different lipids. Aquaculture 151, 131141. 
Dubois, M., Gillies, K.A., Hamilton, J.K., Rebers, P.A., Smith, F. 1956. Colori metric method for the determination of sugars and related substances. Analytical Chemistry 28, 350-356.

Dunstan, G.A. Volkman, J.K., Barrett, S.M. 1993. The effect of lyophilization on the solvent extraction of lipid classes, fatty acids and sterols from the oyster Crassostrea gigas. Lipids 28, 937-944.

Edmunds, M. 1995. The ecology of the juvenile southern rock lobster, Jasus edwardsii (Hutton 1875) (Palinuridae). In: PhD Thesis, University of Tasmania, Hobart. 164 pp.

Evjemo, J.O., Danielsen, T.L., Olsen, Y. 2001. Losses of lipid, protein and n-3 fatty acids in enriched Artemia fransicana starved at different temperatures. Aquaculture 193, 6580.

Handlinger, J.H, Carson, J., Ritar, A.J., Crear, B., Taylor, D., Johnson, D.J. 2001. Disease conditions of cultured phyllosoma larvae and juveniles of the southern rock lobster (Jasus edwardsii, Decapoda; Palinuridae). In: Proceedings of the International Symposium on Lobster Health Management, (Ed. L.H. Evans and J.B. Jones), pp. 7587. Curtin University Publication (http://www.curtin.edu.au/curtin/muresk/hm/index.htm).

Harrison, K.E. 1990. The role of nutrition in maturation, reproduction and embryonic development of decapod crustaceans: A review. Journal of Shellfish Research 9, 1-28.

Illingworth, J., Tong, L.J., Moss, G.A., Pickering, T.D. 1997. Upwelling tank for culturing rock lobster (Jasus edwardsii) phyllosomas. Marine and Freshwater Research 48, 911 914.

Jeffs, A.G., Nichols, P.D., Bruce, M.P. 2001. Lipid reserves used by pueruli of the spiny lobster Jasus edwardsii in crossing the continental shelf of New Zealand. Comparative Biochemistry and Physiology 129A, 305-311.

Johnston, D.J., Ritar, A. 2001. Mouthpart and foregut ontogeny in phyllosoma larvae of the spiny lobster Jasus edwardsii (Decapoda: Palinuridae). Marine and Freshwater Research 52, 1375-1386.

Jones, D.A., Kanazawa, A., Ono, K. 1979. Studies on the nutritional requirements of the larval stages of Peneaus japonicus using microencapsulated diets. Marine Biology 54, 261-267.

Kanazawa A. 1982. Fatty acid metabolism in crustaceans. In: Pruder G.D., Langdon C.J. and Conklin D.E. (Eds.) Proceedings of the Second International Conference on Aquaculture Nutrition: Biochemical and Physiological Approaches to Shellfish Nutrition, pp. 87-105. Louisiana State University Division of Continuing Education, Baton Rouge Louisiana.

Kanazawa, A., Teshima, S., Tokiwa, S. 1977. Nutritional requirements of prawn - VII. Effect of dietary lipids on growth. Bulletin of the Japanese Society of Scientific Fisheries 43, 849-856.

Kanazawa, A., Teshima, S., Ono, K. 1979. Relationship between essential fatty acid requirements of aquatic animals and the capacity for bioconversion of linolenic acid to highly unsaturated fatty acids. Comparative Biochemistry and Physiology 63B, 295298.

Kittaka, J. 1994. Larval rearing. In: Phillips, B. F., Cobb, J. S., Kittaka, J. (Eds.), Spiny Lobster Management. Blackwell Scientific Publications Ltd, Oxford. pp. 402-423.

Koskela, R.W., Greenwood, J.G., Rothlisberg, P.C. 1992. The influence of prostaglandin $\mathrm{E}_{2}$ and the steroid hormones, $17 \alpha$-hydroxyprogesterone and $17 \beta$-estradiol on moulting and ovarian development in the tiger prawn, Penaeus esculentus Haswell, 1879 (Crustacea: Decapoda). Comparative Biochemistry and Physiology 101A, 295-299. 
Kurmaly, K., Jones, D.A., Yule, A.B., East, J. 1989. Comparative analysis of the growth and survival of Peneaus monodon (Fabricus) larvae, from protozoae I to postlarvae I, on live feeds, artificial diets, and on combination of both. Aquaculture 81, 27-45.

Lesser, J.H.R. 1978. Phyllosoma larvae of Jasus edwardsii (Hutton) (Crustacea: Decapoda: Palinuridae) and their distribution off the east coast of the North Island, New Zealand. New Zealand Journal of Marine and Freshwater Research 12, 357-370.

Merchie, G., Lavens, P. and Sorgeloos, P. 1997. Optimization of dietary vitamin C in fish and crustacean larvae: a review. Aquaculture 155: 165-181.

Mikami, S., Greenwood, J.G., Gillespie, N.C., Kittaka, J. 1995. The effect of starvation and feeding regimes on survival, intermoult period and growth of cultured Panulirus japonicus and Thenus sp. phyllosomas (Decapoda, Palinuridae and Scyllaridae). Crustaceana 68, 160-169.

Moss, G., James, P., Tong, L. 2000. Jasus verreauxi phyllosomas cultured. The Lobster Newsletter 13 (1), 9-10.

Navarro, J.C., Henderson, R.J., McEvoy, L.A., Bell, M.V., Amat, F. 1999. Lipid conversions during enrichment of Artemia. Aquaculture 174, 155-166.

Nelson, M.M., Mooney, B.D., Nichols, P.D., Phleger, C.F., Smith, G.G., Ritar, A.J. 2002. The effect of diet on the biochemical composition of juvenile Artemia: potential formulations for rock lobster aquaculture. Journal of the World Aquaculture Society 33, 146-157.

Nelson, M.M., Crear, B.J., Nichols, P.D., Ritz, D.A. 2003. Feeding southern rock lobster, Jasus edwardsii, Hutton, 1875, phyllosomata in culture: recent progress with lipidenriched Artemia. J. Shellfish Res. 22, (in press).

Olsen Y. 1998. Lipids and essential fatty acids in aquatic food webs: what can freshwater ecologists learn from mariculture? In: Arts, M.T., Wainman, B.C. (Eds.), Lipids in Freshwater Ecosystems. Springer, New York, pp. 161-202.

Phillips, B.F., Sastry, A.N. 1980. Larval Ecology. In: Cobb, J. S., Phillips, B. F. (Eds.), The Biology and Management of Lobsters Vol. 2. Academic Press, New York, pp. 1157.

Phleger, C.F., Nelson, M.M., Mooney, B.D., Nichols, P.D., Ritar, A.J., Smith, G.G., Hart, P.R., Jeffs, A.G. 2001. Lipids and nutrition of the southern rock lobster, Jasus edwardsii, from hatch to puerulus. Marine and Freshwater Research 52, 1475-1486.

Pond, D.W., Sargent, J.R. 1998. Lipid composition of the pelagic tunicate Dolioletta gegenbauri (Tunicata, Thaliacea). Journal of Plankton Research 20, 169-74.

Ritar, A.J. 2001. The experimental culture of phyllosoma larvae of southern rock lobster (Jasus edwardsii) in a flow-through system. Aquacultural Engineering 24, 149-156.

Ritar, A.J., Thomas, C.W., Beech, A.R. 2002. Feeding Artemia and shellfish to phyllosoma larvae of southern rock lobster (Jasus edwardsii). Aquaculture 212, 179-190.

Ritar, A.J., Smith, G.G., Dunstan, G.A., Brown, M.R., Hart, P.R. 2003. Size and presentation of Artemia affects the growth and survival of phyllosoma larvae of southern rock lobster (Jasus edwardsii). Aquaculture International (in press).

Roustaian, P., Kamarudin, M.S. Omar, H., Saad, C.R., Ahmad, M.H. 1999. Changes in fatty acid profile during larval development of freshwater prawn Macrobrachium rosenbergii (de Man). Aquaculture Research 30, 815-824.

Roustaian, P., Kamarudin, M.S., Omar, H.B., Saad, C.R., Ahmad, M.H. 2000. Amino acid composition of developing larval freshwater prawn Macrobrachium rosenbergii. Journal of the World Society of Aquaculture 31, 130-136.

Roustaian, P., Kamarudin, M.S., Omar, H.B., Saad, C.R., Ahmad, M.H. 2001. Biochemical changes in freshwater prawn Macrobrachium rosenbergii during larval development. Journal of the World Society of Aquaculture 32, 52-59. 
Sargent A.R. 1995. Origins and functions of egg lipids: nutritional implications. In: Bromage N.R. and Roberts R.J. (Eds.) Broodstock Management and Egg and Larval Quality. Blackwood Science, Oxford, pp. 353-372.

Sargent, J.R., Whittle, K.J. 1981. Chapter 17: Lipids and Hydrocarbons in the Marine Food Web. Analysis of Marine Ecosystems. A. R. Longhurst. London, Academic Press: 491-533.

Sargent, J.R., McEvoy, L., Estevez, A., Bell, G., Henderson, J., Tocher, D. 1999. Lipid nutrition of marine fish during early development: status and future directions. Aquaculture 179, 217-229.

Smith, E.G., Ritar, A.J., Carter, C.G., Dunstan, G.A., Brown, M.R. 2003 a. Photothermal manipulation of reproduction in broodstock and larval characteristics in newly-hatched phyllosoma of the spiny lobster, Jasus edwardsii. Aquaculture 220, 299-311.

Smith, G.G., Ritar, A.J., Phleger, C.F., Nelson, M.M., Mooney, B., Nichols, P.D., Hart, P.R. 2002. Changes in gut content and composition of juvenile Artemia after oil enrichment and during starvation. Aquaculture 208, 137-158.

Smith, G.G., Ritar, A.J., Dunstan, G.A. 2003 b. An activity test to evaluate larval competency in spiny lobsters (Jasus edwardsii) from wild and captive ovigerous broodstock held under different environmental conditions. Aquaculture 218, 293-307.

Smith, G.G., Thompson, P.A., Ritar, A.J., Dunstan, G.A. 2003 c. Effects of starvation and feeding on the fatty acid profiles of Stage I phyllosoma of the spiny lobster, Jasus edwardsii. Aquaculture Research 34, 419-426.

Sokal R.R., Rohlf J.F. 1995. Biometry: The principles and practice of statistics in biological research. Freeman. New York, 468p.

Takeuchi, T., Watanabe, T. 1982. The effects of starvation and environmental temperature on proximate and fatty acid compositions of carp and rainbow trout. Bulletin of the Japanese Society of Scientific Fisheries 48, 1307-1316.

Teshima, S., Kanazawa, A. 1971. Biosynthesis of sterols in the lobster, Penaeus japonicus, and the crab, Portunus trituberculatus. Comparative Biochemistry and Physiology 38B, 597-602.

Teshima, S., Kanazawa, A. 1982. Variation in lipid compositions during the larval development of the prawn (Peneaus japonicus). Memoirs of the Faculty of Fisheries, Kayoshima University 31, 205-212.

Teshima, S.J., Kanazawa, A., Yamashita, M. 1986. Dietary value of several proteins and supplemental amino acids for larvae of the prawn Peneaus japonicus. Aquaculture 51, 225-235.

Teshima, S.J., Kanazawa, A., Hitotsumatsu, K., Kim, K.S., Oshida, K., Koshio, S. 1992. Tissue uptake and bioconversion of eicosapentaenoic acid and phosphatidylcholine in prawns, Peneaus and Macrobrachium. Comparative Biochemistry and Physiology 102B, 885-890.

Tong, L. J., Moss, G.A., Paewai, M., Pickering, T.D. 1997. Effect of brine shrimp numbers on the growth and survival of early stage phyllosoma larvae of the rock lobster Jasus edwardsii. Marine and Freshwater Research 48, 935-940. 
Table 1. Dry weight and percentage content of protein, lipid and carbohydrate in fed and starved spiny lobster, Jasus edwardsii, phyllosoma larvae from hatch to Stage VI, and of enriched Artemia. Data are mean \pm SEM values.

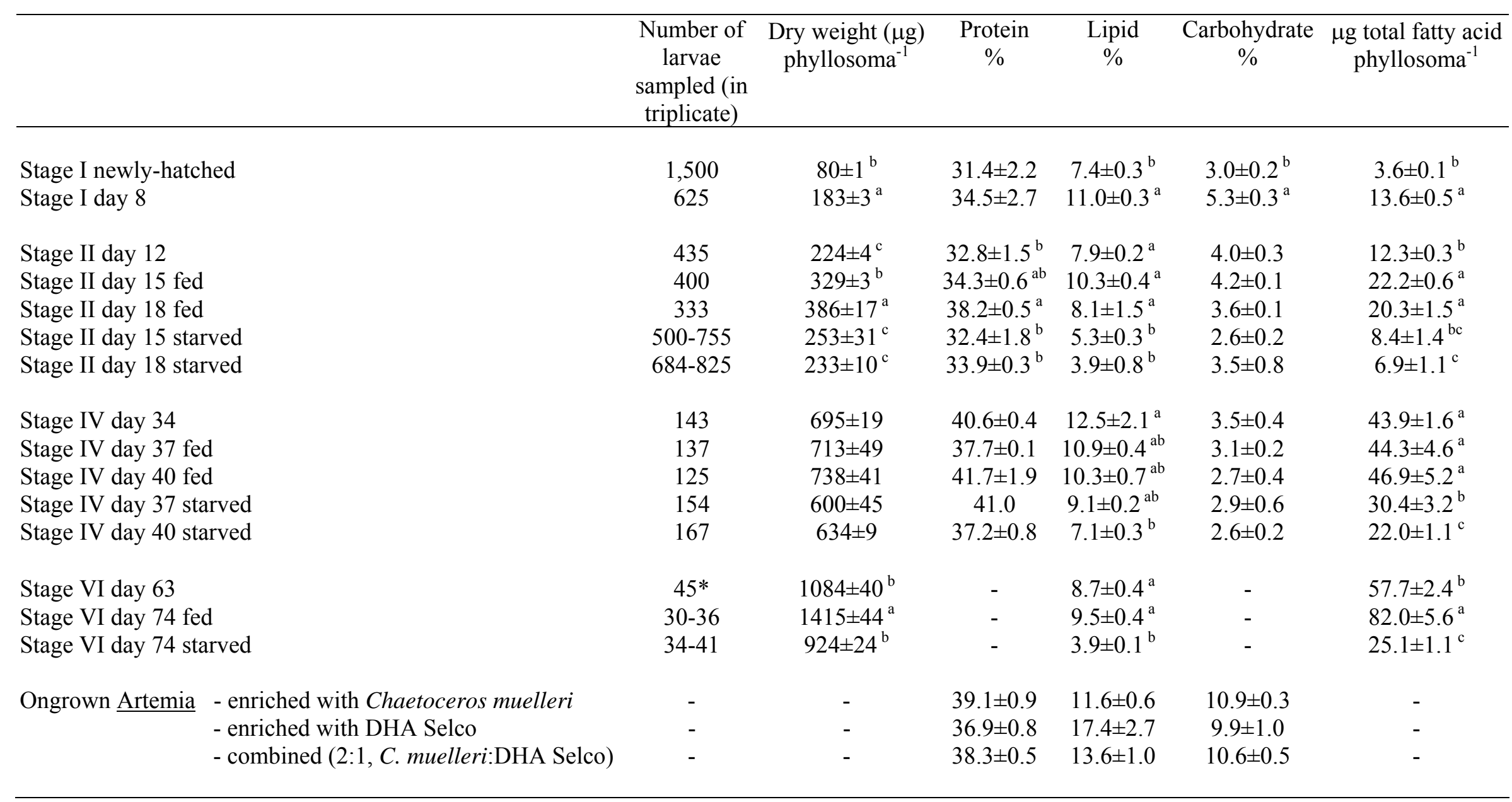

Different superscripts indicate significant differences $(\mathrm{P}<0.05)$ within stages of phyllosoma development.

* indicates that $>50 \%$ of larvae were at early Stage VI. 
Table 2. Fatty acid composition (mean \% of total fatty acids) of spiny lobster, Jasus edwardsii phyllosoma larvae at hatch, after feeding or starvation at Stages II, IV and VI, and of enriched Artemia. Data are mean values. Only the major fatty acids, present at $\geq 1 \%$ at some stage, are included.

\begin{tabular}{|c|c|c|c|c|c|c|c|c|c|c|c|c|c|c|c|c|c|c|c|c|}
\hline \multirow[b]{2}{*}{ Fatty acid } & \multicolumn{2}{|c|}{ Stage I } & \multicolumn{5}{|c|}{ Stage II } & \multicolumn{5}{|c|}{ Stage IV } & \multicolumn{3}{|c|}{ Stage VI } & \multicolumn{3}{|c|}{${\text { Enriched } \text { Artemia }^{1}}^{1}$} & \multicolumn{2}{|c|}{ Enrichments } \\
\hline & Newly- & $\overline{\mathrm{D} 8}$ & $\overline{\text { D12 }}$ & $\begin{array}{l}\text { D15 } \\
\text { Fed }\end{array}$ & D18 & $\begin{array}{r}\text { D15 } \\
\text { Starved }\end{array}$ & $\begin{array}{r}\mathrm{D} 18 \\
\text { Starved }\end{array}$ & $\overline{\mathrm{D} 34}$ & $\begin{array}{l}\text { D37 } \\
\text { Fed }\end{array}$ & D40 & $\begin{array}{r}\text { D37 } \\
\text { Starved }\end{array}$ & $\begin{array}{r}\mathrm{D} 40 \\
\text { Staryed }\end{array}$ & $\bar{D} 63$ & D74 & $\begin{array}{r}\mathrm{D} 74 \\
\text { Starved }\end{array}$ & C. $m$. & $\overline{\text { DHAS }}$ & $\overline{2: 1}$ & C. $m$. & $\overline{\text { DHAS }}$ \\
\hline $14: 0$ & 0.6 & 1.0 & 0.9 & $\begin{array}{c}\text { Fed } \\
0.8\end{array}$ & $\begin{array}{c}\text { Fed } \\
0.8\end{array}$ & $\frac{r \text { Starved }}{0.7}$ & $\begin{array}{r}\text { Starved } \\
0.6\end{array}$ & 0.7 & $\frac{F e d}{0.6}$ & $\frac{\text { Fed }}{0.6}$ & $\begin{array}{r}\text { Starved } \\
0.7\end{array}$ & $\begin{array}{r}\text { Starved } \\
0.6\end{array}$ & 0.5 & $\frac{\mathrm{Fed}}{0.5}$ & $\begin{array}{r}\text { Starved } \\
0.5\end{array}$ & 1.4 & 1.5 & 1.5 & 8.8 & 3.6 \\
\hline 16:0 & 13.9 & 12.2 & 11.4 & 11.3 & 11.4 & 11.6 & 11.4 & 10.6 & 10.2 & 10.4 & 11.2 & 11.4 & 10.9 & 10.8 & 12.4 & 8.5 & 11.8 & 9.6 & 5.1 & 19.8 \\
\hline 17:0 & 1.4 & 1.0 & 1.1 & 1.0 & 1.0 & 1.3 & 1.2 & 0.9 & 0.9 & 1.0 & 1.1 & 1.1 & 1.0 & 0.8 & 1.1 & 0.5 & 0.7 & 0.6 & 0.2 & 1.3 \\
\hline 18:0 & 6.9 & 8.8 & 9.5 & 9.2 & 9.3 & 10.6 & 10.6 & 9.5 & 11.2 & 9.9 & 11.2 & 12.1 & 8.7 & 8.0 & 10.0 & 5.4 & 5.4 & 5.4 & 0.8 & 5.8 \\
\hline 20:0 & 0.8 & 0.5 & 0.8 & 0.7 & 0.6 & 0.9 & 1.3 & 0.5 & 1.0 & 0.6 & 0.7 & 0.8 & 0.5 & 0.4 & 0.6 & 0.2 & 0.3 & 0.2 & 0.9 & 0.6 \\
\hline $22: 0$ & 0.7 & 0.8 & 1.0 & 1.0 & 1.0 & 1.0 & 1.8 & 1.2 & 3.4 & 1.7 & 1.8 & 2.5 & 1.0 & 0.8 & 1.5 & 0.7 & 0.6 & 0.6 & 0.2 & 0.3 \\
\hline $16: 1 n-9$ & 0.5 & 0.8 & 0.7 & 0.7 & 0.8 & 0.6 & 0.5 & 0.7 & 0.7 & 0.7 & 0.7 & 0.6 & 0.8 & 0.9 & 0.7 & 1.2 & 1.0 & 1.1 & 0.1 & 0.4 \\
\hline $16: 1 n-7$ & 3.4 & 4.6 & 4.0 & 3.7 & 3.6 & 3.0 & 2.4 & 3.1 & 2.5 & 2.4 & 2.6 & 2.3 & 2.3 & 2.3 & 1.7 & 4.6 & 3.3 & 4.2 & 22.8 & 4.3 \\
\hline $18: \ln -9$ & 12.3 & 19.3 & 18.5 & 20.9 & 20.2 & 16.5 & 14.6 & 21.6 & 20.7 & 22.6 & 19.0 & 18.2 & 24.0 & 25.3 & 19.6 & 29.7 & 26.4 & 28.6 & 0.8 & 13.6 \\
\hline $18: 1 \mathrm{n}-7$ & 4.8 & 7.7 & 7.6 & 8.2 & 8.6 & 7.1 & 6.8 & 7.9 & 7.5 & 7.1 & 8.3 & 7.6 & 6.8 & 6.5 & 6.6 & 5.5 & 4.6 & 5.2 & 0.8 & 2.6 \\
\hline $20: 1 n-9$ & 1.9 & 1.1 & 1.3 & 1.1 & 1.1 & 1.4 & 1.7 & 1.2 & 1.1 & 1.2 & 1.2 & 1.2 & 1.2 & 1.1 & 1.1 & 0.6 & 0.7 & 0.7 & 0.0 & 0.8 \\
\hline $18: 2 n-6$ & 1.0 & 11.3 & 11.0 & 12.9 & 12.0 & 9.2 & 8.1 & 14.7 & 14.6 & 15.7 & 12.7 & 12.1 & 17.1 & 18.7 & 13.6 & 24.0 & 19.4 & 22.4 & 0.9 & 5.5 \\
\hline $20: 2 n-6$ & 1.6 & 1.4 & 1.8 & 1.7 & 1.7 & 2.2 & 2.6 & 2.2 & 2.1 & 2.3 & 2.4 & 2.5 & 2.7 & 2.7 & 3.2 & 0.7 & 0.6 & 0.6 & 0.1 & 0.4 \\
\hline $20: 4 n-6$, AA & 7.0 & 3.2 & 3.8 & 3.1 & 3.1 & 4.6 & 5.3 & 3.4 & 3.2 & 3.3 & 3.9 & 4.2 & 3.4 & 3.2 & 4.9 & 1.4 & 1.5 & 1.4 & 1.6 & 1.7 \\
\hline 20:5n-3, EPA & 17.1 & 11.0 & 11.4 & 10.2 & 10.5 & 13.1 & 14.4 & 10.3 & 9.6 & 9.5 & 10.9 & 11.2 & 10.0 & 9.5 & 11.7 & 5.5 & 5.1 & 5.4 & 20.4 & 5.2 \\
\hline $22: 5 n-3$ & 1.1 & 0.3 & 0.2 & 0.2 & 0.2 & 0.2 & 0.2 & 0.2 & 0.2 & 0.2 & 0.1 & 0.2 & 0.2 & 0.2 & 0.2 & 0.0 & 0.4 & 0.1 & 0.0 & 1.0 \\
\hline 22:6n-3, DHA & 10.7 & 3.7 & 3.7 & 3.0 & 2.8 & 4.7 & 5.4 & 2.6 & 2.6 & 2.9 & 2.8 & 3.1 & 3.2 & 2.8 & 4.3 & 0.5 & 7.0 & 2.7 & 1.0 & 21.0 \\
\hline Sum SFA & 25.2 & 24.8 & 25.2 & 24.3 & 24.6 & 26.5 & 27.3 & 23.8 & 27.7 & 24.6 & 27.0 & 28.9 & 22.7 & 21.7 & 26.5 & 17.0 & 20.9 & 18.3 & 16.5 & 32.7 \\
\hline Sum MUFA & 28.3 & 36.3 & 34.8 & 37.0 & 37.2 & 31.5 & 29.1 & 36.6 & 34.4 & 36.0 & 34.0 & 32.3 & 36.7 & 37.7 & 31.6 & 43.3 & 38.4 & 41.7 & 27.7 & 25.2 \\
\hline Sum PUFA & 44.0 & 37.7 & 38.7 & 37.9 & 37.3 & 41.0 & 42.8 & 38.2 & 36.6 & 38.1 & 37.6 & 37.4 & 39.8 & 39.9 & 41.1 & 37.4 & 39.5 & 38.1 & 53.0 & 41.3 \\
\hline Other $^{2}$ & 2.5 & 1.2 & 1.3 & 0.8 & 0.9 & 1.0 & 0.8 & 1.4 & 1.3 & 1.3 & 1.4 & 1.5 & 0.8 & 0.7 & 0.9 & 2.3 & 1.2 & 1.9 & 2.7 & 0.8 \\
\hline$n-3$ & 30.0 & 19.4 & 19.4 & 18.0 & 18.1 & 21.9 & 23.8 & 16.0 & 14.9 & 15.0 & 16.4 & 16.7 & 14.8 & 14.0 & 17.3 & 8.8 & 15.4 & 11.0 & 22.7 & 15.4 \\
\hline$n-6$ & 11.1 & 17.2 & 18.0 & 18.8 & 18.1 & 17.6 & 17.6 & 21.4 & 20.8 & 22.3 & 20.3 & 19.7 & 24.1 & 25.2 & 22.4 & 27.5 & 23.1 & 26.1 & 3.6 & 23.1 \\
\hline$n-3: n-6$ & 2.7 & 1.1 & 1.1 & 1.0 & 1.0 & 1.2 & 1.4 & 0.7 & 0.7 & 0.7 & 0.8 & 0.8 & 0.6 & 0.6 & 0.8 & 0.3 & 0.7 & 0.4 & 6.8 & 0.7 \\
\hline DHA:EPA:AA & $10: 16: 7$ & 10:30:9 & 10:31:10 & 10:36:11 & 10:40:11 & 10:28:10 & 10:29:10 & 10:40:13 & 10:38:13 & 10:32:12 & $10: 38: 14$ & 10:36:14 & 10:32:11 & 10:35:12 & 10:27:12 & $10: 117: 30$ & $10: 7: 2$ & $10: 20: 5$ & $10: 202: 161$ & $: 2.5: 0.8$ \\
\hline
\end{tabular}

Artemia were enriched with either Chaetoceros muelleri (C. m.) or DHA Selco (DHAS) before combining at a rate of 2:1.

${ }^{2}$ Other includes components present at <1\%: i15:0. a15:0, i16:0, C16 PUFA, 16:1(n-5)c, i18:0, 18:3(n-6)c, 18:3(n-3)c, 18:1(n-7)t, 18:1(n-5), i19:0, 19:1, 20:3(n-6), 20:4(n-3), 20:1(n-7)c,

C21 PUFA, 21:0, 22:5(n-6), 22:3(n-3), 22:1(n-7), 22:0, 24:1, 24:0. 


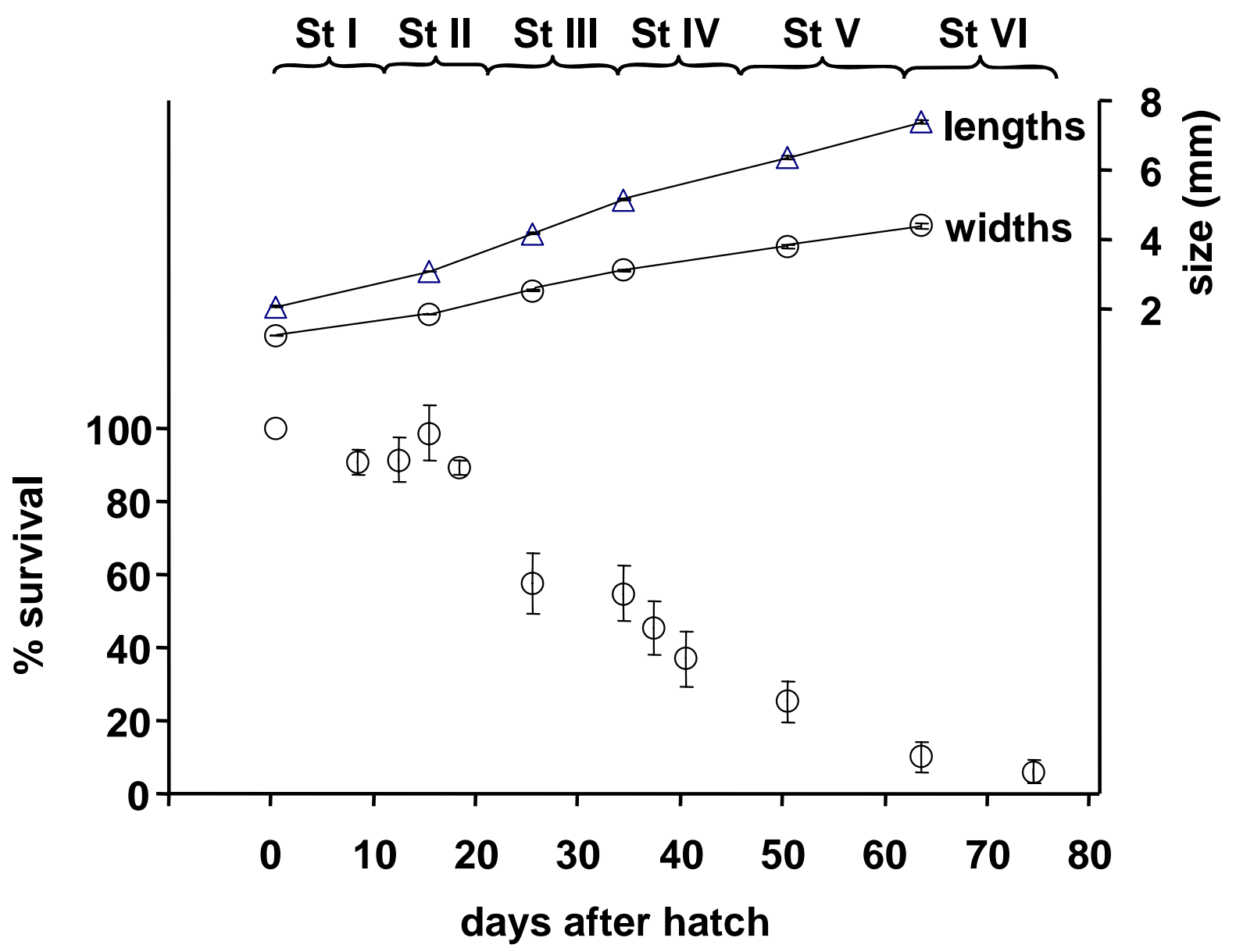

Fig. 1. Survival (\%) from hatch and body lengths and widths (mm) of spiny lobster, Jasus edwardsii, phyllosoma larvae cultured from hatch to Stage VI. Data are presented as mean \pm SEM.
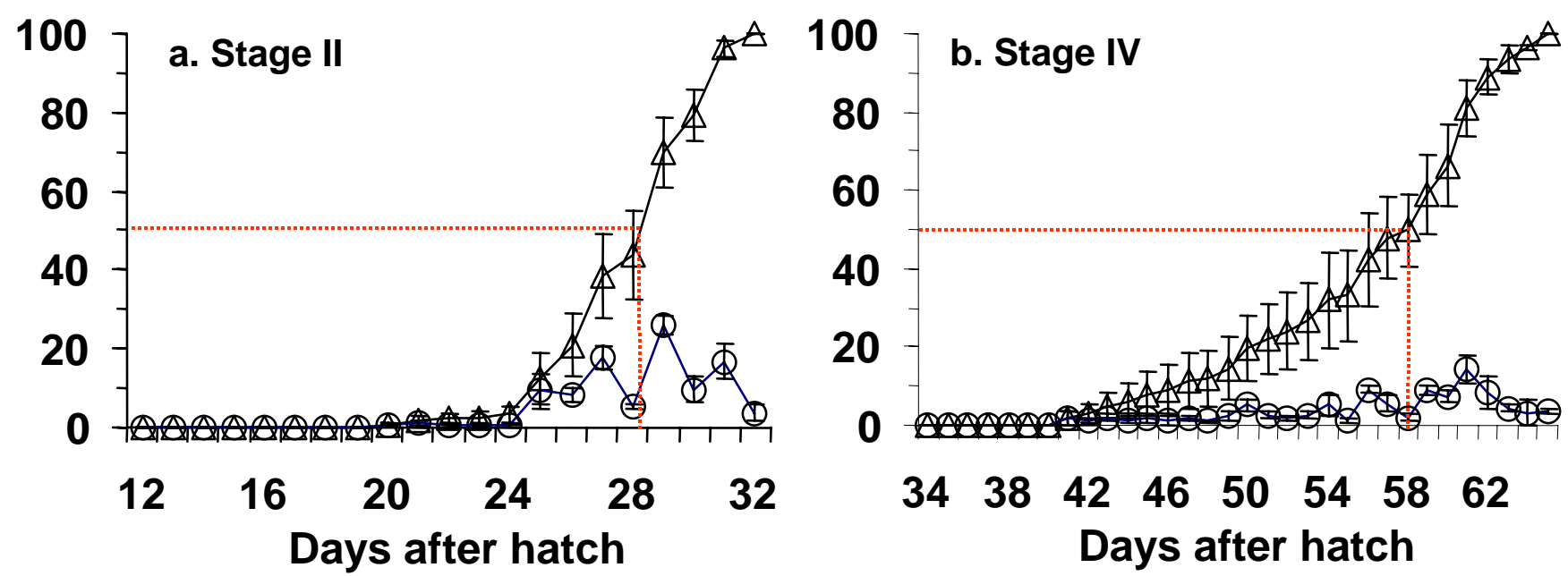

Fig. 2. Daily (circles) and cumulative (triangles) mortalities (\% mean \pm SEM) during starvation of spiny lobster, Jasus edwardsii, phyllosoma larvae at a. Stage II and b. Stage IV. 

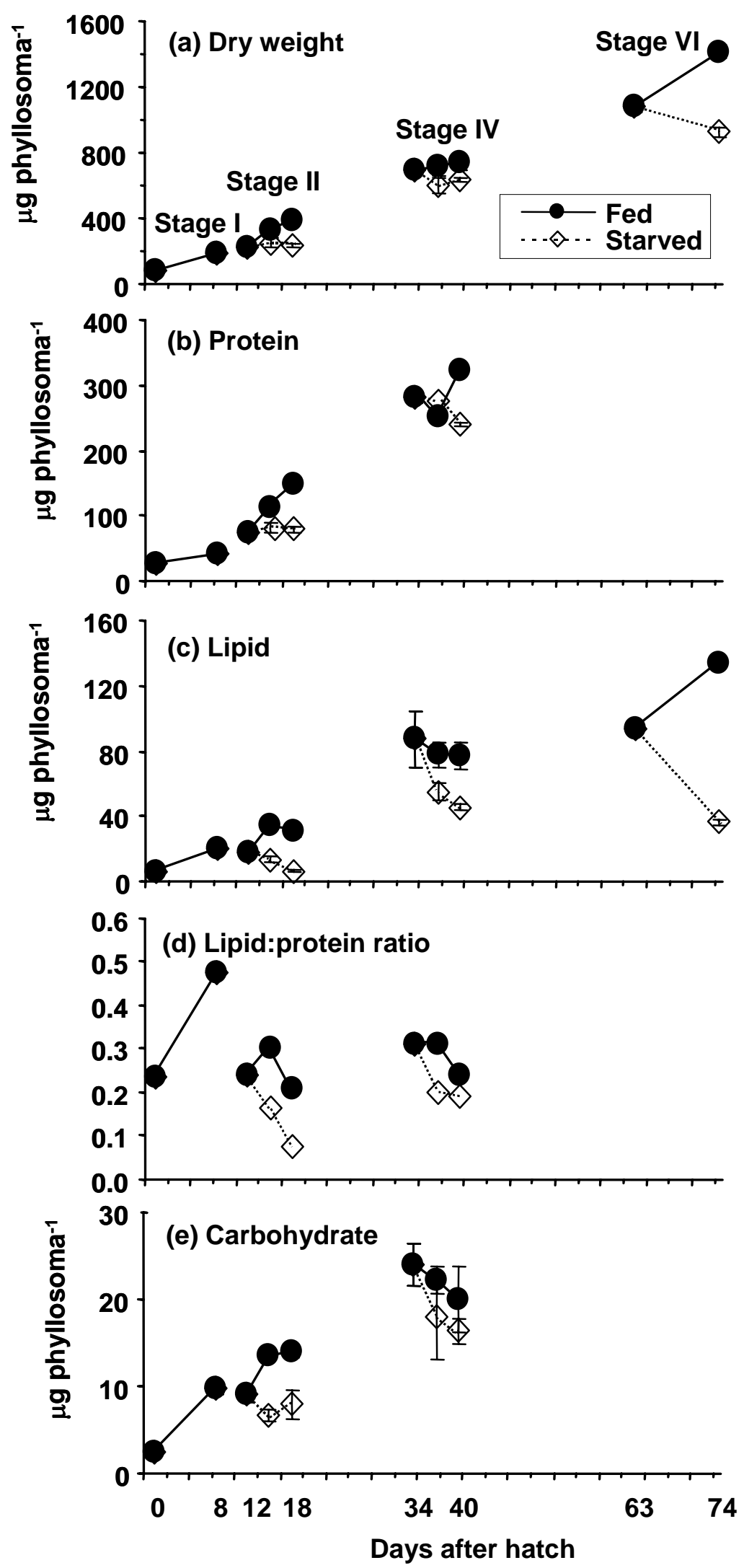

Fig. 3. Major proximate components of fed (closed circles) and starved (open circles) spiny lobster, Jasus edwardsii, phyllosoma larvae from hatch to Stage VI: (a) dry weight, (b) protein, (c) lipid, (d) lipid:protein ratio, and (e) carbohydrate. Data are presented as mean \pm SEM. 


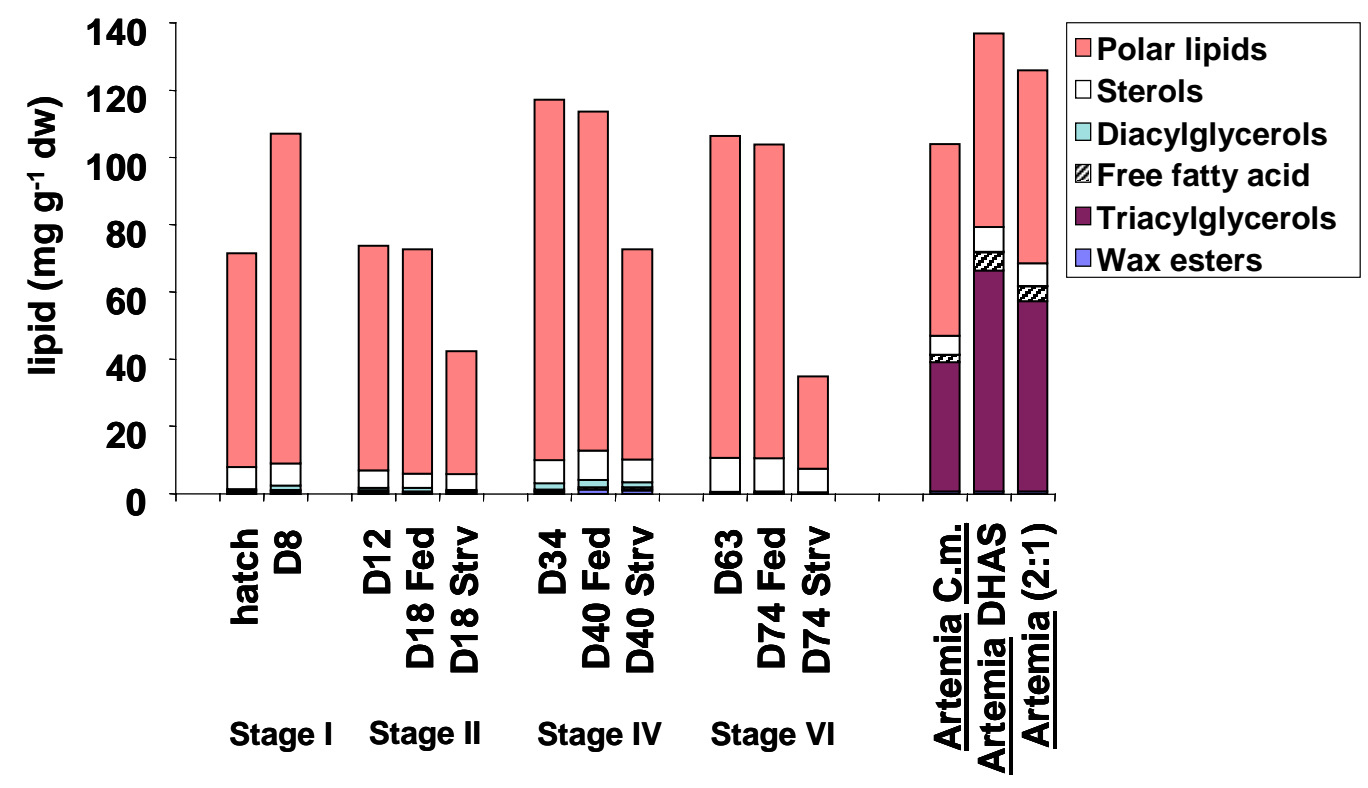

Fig. 4. Lipid content ( $\mathrm{mg} \mathrm{g}^{-1}$ dry weight) and lipid classes of spiny lobster, Jasus edwardsii, phyllosoma larvae during feeding and starvation from hatch until Stage VI and in Artemia. Artemia (2:1) were enriched with Chaetoceros muelleri (Artemia_C. m.) or DHA Selco (Artemia DHAS) and combined at a ratio of 2:1. 


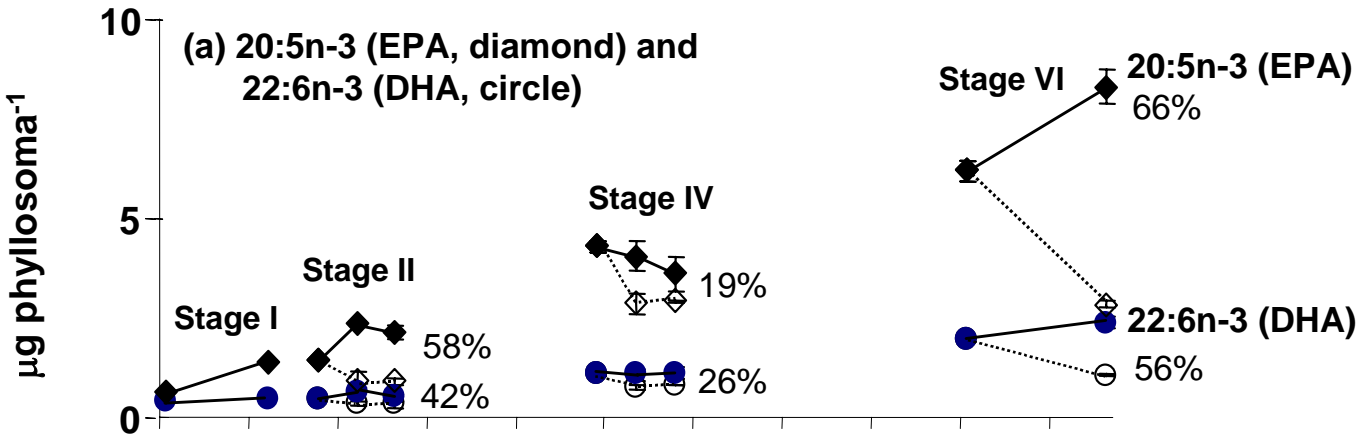

(b) 18:2n-6 (diamond) and
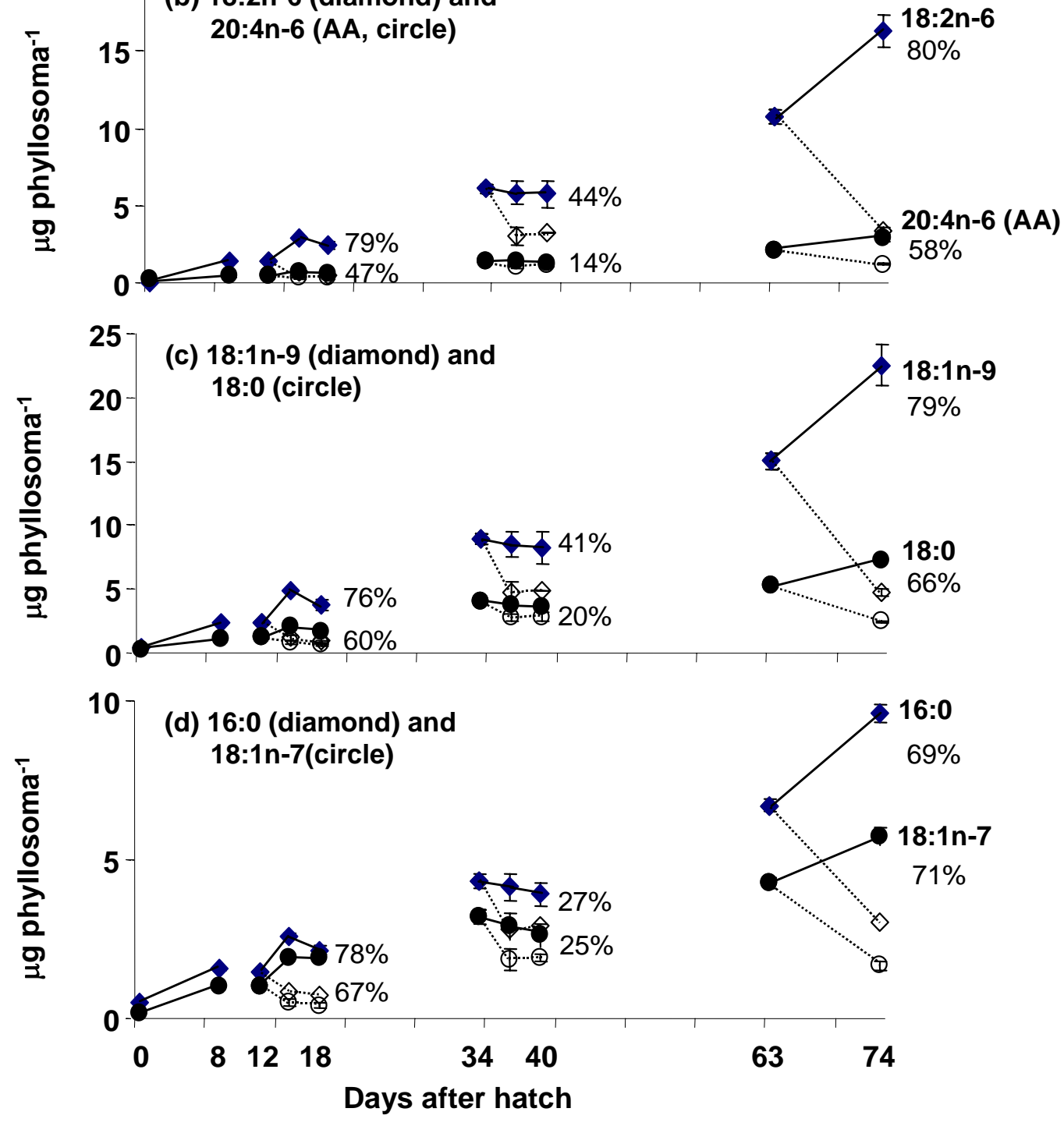

Fig. 5. Dry weights (dw, mean \pm SEM $\mu$ g phyllosoma ${ }^{-1}$ ) of major fatty acids in fed (closed symbols) and starved (open symbols) spiny lobster, Jasus edwardsii, phyllosoma larvae from hatch to Stage VI. (a) 20:5n-3 (EPA) and 22:6n-3 (DHA), (b) 18:2n-6 and 20:4n-6 (ARA), (c) 18:1n-9 and 18:0, and (d) 16:0 and 18:1n-7. Percentages indicate the differences between fed and starved larvae at the ends of Stages II, IV and VI. 